\title{
ANALYZE THE IMPACT OF HABITAT PATCHES ON WILDLIFE ROAD-KILL
}

\author{
S. Seok ${ }^{\mathrm{a}}$, J. Lee ${ }^{\mathrm{a}, *}$ \\ ${ }^{a}$ Dept. of Geoinformatics, The University of Seoul, 163 Seoulsiripdaero, Seoul, South Korea - (rltk00, jlee@uos.ac.kr)
}

KEY WORDS: Road-kill, Correlation analysis, Habitat Patches, Hotspots

\begin{abstract}
:
The ecosystem fragmentation due to transportation infrastructure causes a road-kill phenomenon. When making policies for mitigating road-kill it is important to select target-species in order to enhance its efficiency. However, many wildlife crossing structures have been questioned regarding their effectiveness due to lack of considerations such as target-species selection, site selection, management, etc. The purpose of this study is to analyse the impact of habitat patches on wildlife road-kill and to suggest that spatial location of habitat patches should be considered as one of the important factors when making policies for mitigating road-kill. Habitat patches were presumed from habitat variables and a suitability index on target-species that was chosen by literature review. The road-kill hotspot was calculated using Getis-Ord $G i^{*}$. After that, we performed a correlation analysis between $G i \mathrm{Z}$ score and the distance from habitat patches to the roads. As a result, there is a low negative correlation between two variables and it increases the $\mathrm{Gi}$ Z-score if the habitat patches and the roads become closer.
\end{abstract}

\section{INTRODUCTION}

The ecosystem fragmentation due to transportation infrastructure causes a road-kill phenomenon. According to the report, after installing a wildlife crossing structure for amphibians in 2006, road-kill occurrence of amphibians declined from 986 cases (2006) to 71 cases (2012), by approximately 92\% (Korea National Park Research Institute, 2013). In other words, when making policy for mitigating roadkill it is important to select target-species in order to enhance its efficiency.

In this paper, we are to grasp the relationship between roadkill hotspots and habitat patches, and we will suggest that spatial location of habitat patches should be considered as one of the important factors for mitigating road-kill. This paper is organized as follows; Section 2 reviews limitations in current research on mitigating wildlife road-kill, Section 3 proposes methodology of this study, and Section 4 describes the experimental implementation. The final section concludes with a discussion of future work.

\section{LIMITATION OF CURRENT RESEARCH ON MITIGATING WILDLIFE ROAD-KILL}

By its nature, the road-kill phenomenon occurred on the road, and the occurrence factor of road-kill varies from traffic to ecological factors such as traffic volume, operating speed, etc. (Choi, 2007). As mentioned previously, target-species is an important factor to increase efficiency of the wildlife crossing structure. Their ecological characteristics also reflect that. Park et al.(2012) attempted to identify a potential wildlife passage site for leopard cats(Prionailurus bengalensis euptilura) utilizing radio-tracking data captured during the four-month period and proposed suitable site for installing crossing structure (Park et al., 2012). Besides that, many researchers have proposed to set up measure for mitigating wildlife roadkill through categorization of road-kill characteristics based on accumulated road-kill data over time such as types of road, maximum speed limit, land use, etc. (Lee \& Lee, 2006; Shin \& Ahn, 2008, Choi et al., 2012).

Such microscopic studies utilizing accumulated data have the advantage of more precise and reliable in analysis results. Nevertheless, since the data acquisition period is too long and the results are obtained within a single region, the scope of application is limited. With a view to improving such limitations, this paper proposes ways of identifying a correlation between habitat patches and road-kill hotspots in macro perspective. Because habitat patches of target-species can be repeatedly utilized in many regions, it has benefits compared with other approaches on the recyclability side.

\section{METHODOLOGY}

The purpose of this study is to analyse the impact of habitat patches on wildlife road-kill, so the entire procedure for analysis is summarized as follows;

Step 1: Presumption of Habitat Patches

Step 2: Correlation Analysis between Habitat Patches and Road-kill Hotspots

\subsection{Presumption of Habitat Patches}

For accurate presumption of habitat patches, it will be desired to utilize a well formulated Habitat Suitability Index (HSI). However, it is impossible to formulate HSI of all species existing on earth, and for such a reason, HSI has been formulated for endangered species or principal species.

In this paper, we determine a Habitat Variable (HV) and Suitability Index (SI) based on ecological characteristics of target-species, and then presume their habitat patches using a weighted overlay method in GIS. Here, weights-related to HVs are calculated by Rank Order Centroid (ROC) (Edward \& Barron, 1994) (1) according to their priority.

\footnotetext{
* Corresponding author
} 


$$
w_{i}(R O C)=\frac{1}{n} \sum_{j=1}^{n} \frac{1}{j} \quad i=1 \cdots n
$$

When HVs, SIs, and their weights are determined, it is classified into two-groups (suitable habitats and unsuitable habitats) using quantile classification after the weighted overlay model (Lee \& Zarine Kemp, 1997) (2). After that, habitat patches of target-species are finally presumed from consideration of their territory.

$$
v=\sum_{i=1}^{M} w_{i} u_{i}\left(x_{i}\right)
$$

\section{where $\quad \sum_{i=1}^{n} W_{i}=1$}

$w_{i}$ is the weighting associated with attribute $i$, $u_{i} \mathrm{i}[0,1]$ is the utility function associated with attribute $i$,

$x_{i}$ is the attribute (Suitability variable)

\subsection{Correlation Analysis between Habitat Patches and Road-kill Hotspots}

In this paper, we use Getis-Ord $G i^{*}$ (3) to calculate road-kill hotspots. To take advantage of road-kill spot data (POINT), the data are aggregated using grid (POLYGON), and then grid (cell) size is determined by one neighbor distance between the spot data. Finally, we performed a correlation analysis between Gi Z-score and the distance from the habitat patches to the roads.

$$
G^{*}(d)=\frac{\sum j W_{i j}(d) x_{j}-W_{i}^{*} \bar{x}^{*}}{s^{*}\left\{\left[\left(n S^{*} 1 i\right)-W_{i}^{* 2}\right] /(n-1)\right\} 1 / 2}
$$

where $\quad w_{i j}(d)$ is the spatial weight vector with values for all cells,

$j$ is within distance $\mathrm{d}$ of target cell $i$,

$w^{*}{ }_{i}$ is the sum of weights,

$S_{i}{ }^{*}$ is the sum of squared weights,

$s^{*}$ is the standard deviation of the data in the cells

\section{EXPERIMENTAL IMPLEMENTATION}

\subsection{Research Area and Target-Species}

Mt. Odae National Park, of all national parks in Korea, has the second highest road-kill rate (Korea National Park Research Institute, 2013). According to road-kill data collected April 2006 - June 2014, mammal accounted for the highest number of cases (479) followed by reptilia (225), amphibian (220), aves (159). Additionally, it is found that the Siberian Chipmunk from Korea (Tamias sibiricus barberi) has the highest proportion $(70 \%, 334)$ of mammal road-kill cases. Therefore, we selected Mt. Odae National Park and the Siberian Chipmunk as the research area and target-species.

\subsection{HSI Model for Siberian Chipmunk}

The Siberian chipmunk (Tamias sibiricus Laxmann 1769) is distributed from north European and Siberian Russia to Sakhalin, including Korea and Japan (Hoffmann et al. 1993). Johnson and Jones (1955) classified the Siberian Chipmunk from the central and southern regions of Korea into a new subspecies, barberi (Koh et al., 2009).

HVs based on the ecological characteristics of the Siberian Chipmunk are summarized as follows; (1) Ground Coverage (GC), (2) Age Class (AC), 3) Diameter Class (DC), (4) Forest physiognomy (FP), (5) Distance from the Road (DfromR). Each $\mathrm{HV}$ is defined in the following section.

4.2.1 Ground Coverage: It is found that The Siberian chipmunk lives in a wide range of environmental conditions primarily covered by forests (Yoon et al., 2004). Therefore, we determine fuzzy membership which has a negative sloped linear transformation with a using fuzzy logic. Any value above $100(\mathrm{~m})$ will be assigned a 0 .

4.2.2 Age-Class: The Siberian Chipmunk prefers short trees rather than tall trees (Yoon et al., 2004). In this paper, we presume that the higher age-class trees have, the taller they are. Thus, SI of AC is classified as follow; class 1 (1), class $2(0.8)$, class $3(0.6)$, class $4(0.4)$, class $5 / 6(0.2)$, class $7(0)$.

4.2.3 Diameter Class: Earlier research (Han et al., 2009) found that a tree's height is related to diamter at breast height. Thus, SI of DC is classified as follow; class 1 (1), class $2(0.8)$, class 3 (0.6).

4.2.4 Forest Physiognomy: It is found that the Siberian Chipmunk prefers coniferous forests rather than deciduous forests (Yoon, 1992). Thus, SI of FP is classified as follow; coniferous forests (1), mixed forest (0.8), broadleaved forest (0.6), non-stocked forest land (0.4), cultivated land (0.2), etc. $(0)$.

4.2.5 Distance from the Roads: Earlier research (Road Environmental Research Institute, 1995) found that if the roads and forest are separated by over $400(\mathrm{~m})$, road-kill of small mammals such as Japanese hare (Lepus brachyurus) and Japanese weasel (Mustela itatsi) has not occurred. Therefore, we determine fuzzy membership which has a positive sloped linear transformation with a using fuzzy logic. Any value above 400(m) will be assigned a 1 .

4.2.6 Weights: With reference to a research study (Shin, 2013), weights to each habitat variables calculated by using ROC are determined as follow; (1) GC (0.46), (2) AC (0.26), (3) DC (0.15), (4) FP (0.09), (5) DfromR (0.04).

\subsection{Presumption of Habitat Patches of the Siberian Chipmunk and Correlation Analysis}

Figure 1 shows presumed habitat patches of the Siberian Chipmunk in Mt. Odae National Park. The patches include district where the many Siberian Chipmunks are observed in the 2004 survey (red box in Figure 1). In this area, national highway route 6 has more road-kill hotspots (222 spots) compared with local road route 446 (75 spots) and habitat patches is closer to route 6 than route 446 .

The correlation coefficient between $\mathrm{Gi}$ Z-score and distance from habitat patches to the roads was -.281 . After reclassifying variables based on maximum speed limit $(\mathrm{km} / \mathrm{h})(40,50,60$, no speed limit), it showed different results in cases of the speed limit as $60 \mathrm{~km} / \mathrm{h}$ (correlation coefficient $=.518$ ) and no speed limit (correlation coefficient $=-0.072$ ). Thus, the correlation coefficient increased to -.369 after analyzing the correlation between the two variables except for the zone of speed limit as $60 \mathrm{~km} / \mathrm{h}$ and no speed limit. To summarize, there is a low negative correlation between the two variables and it increases 
the Gi Z-score if the habitat patches and the roads become closer (Table 1). However, even though the distance is close, it is found that accident frequency rates are low in cases of the speed limit as $60 \mathrm{~km} / \mathrm{h}$ or higher zones.

$* \mathrm{p}<0.05$

\begin{tabular}{|c|l|c|}
\hline \multicolumn{2}{|c|}{} & Distance \\
\hline \multirow{4}{*}{$\begin{array}{c}G i \\
\text { Z-Score }\end{array}$} & Correlation coefficient (whole) & $-.281^{*}$ \\
\cline { 2 - 3 } & Correlation coefficient $(60 \mathrm{~km} / \mathrm{h})$ & $.518^{*}$ \\
\cline { 2 - 3 } & Correlation coefficient $($ no speed limit) & $-0.072^{*}$ \\
\cline { 2 - 3 } & Correlation coefficient $(40 \& 50 \mathrm{~km} / \mathrm{h})$ & $-.369^{*}$ \\
\hline
\end{tabular}

Table 1. Correlation coefficient between two variables

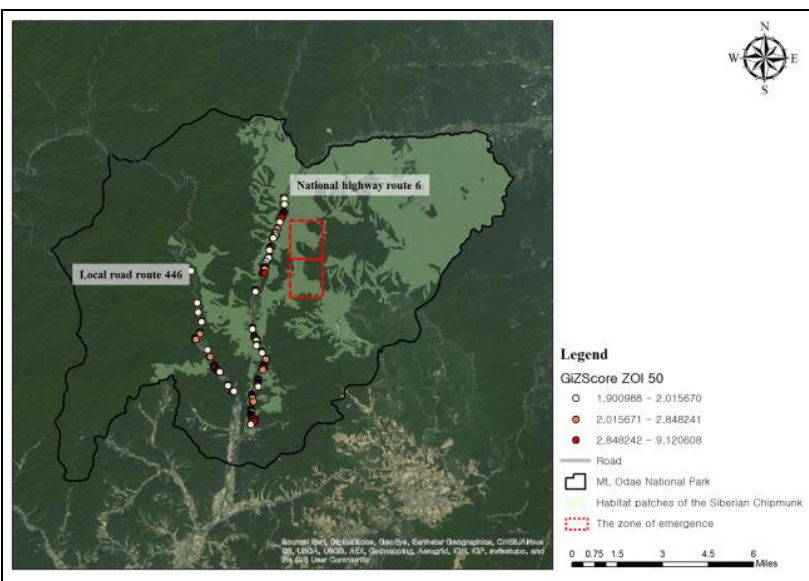

Figure 1. Habitat patches and Road-kill Hotspots of the Siberian Chipmunk in Mt. Odae National Park

\section{CONCLUSION AND FUTURE WORK}

The purpose of this study is to analyse the impact of habitat patches on wildlife road-kill. As a result, there is a low negative correlation between $G i$ Z-score and distance from habitat patches to the roads. Thus, it affects the $G i \mathrm{Z}$-score going up if the habitat patches and the roads become closer and suggests that spatial location of habitat patches should be considered as one of the important factors for mitigating road-kill.

As mentioned previously, for accurate presumption of habitat patches, it is desired to utilize well formulated HSI. HSI for the Siberian Chipmunk proposed in this paper is based on only literature review in research. In other words, quantitative analysis is required to validate presumed patches in this study.

In the next steps, we will need to consider additional data achieved through field survey about wildlife and habitat. It allows researcher to more precisely and easily presume the habitat patches in the field where it is hard to survey. Consequently, it will be effectively utilized as an important factor to presume dangerous stretch of road.

\section{ACKNOWLEDGEMENTS}

This research was supported a grant from geospatial information workforce development program funded by the Ministry of Land, Infrastructure and Transport of Korean Government (2014-04-05)

\section{REFERENCES}

Choi TY, Yang BG, Woo DG., 2012. The Suitable Types and Measures of Wildlife Crossing Structures for Mammals of
Korea, Journal of the Environment Impact Assessment, 21(1), 209-218.

Choi TY., 2007. Road-Kill Mitigation Strategies for Mammals in Korea: Data Based on Surveys of Road-kill, Non-wildlife Passage Use, and home-range, ph.D dissertation, Seoul National University, Korea.

Edward W, Barron FH., 1994. SMARTS and SMARTER: Improved Simple Methods for Multiattribute Utility Measurement, Organizational Behavior and Human Decision Processes, 60, 306-325.

Han SH, Rho DK, Jung JH, Kim SH, Jung DJ., 2009, Estimation of hight-DBH models for Ulmus davidiana by national forest inventory data, Proceeding of Korean Forest Society, 432-434.

Hoffmann RS, Anderson CG, Thorington RW, Heaney LR, 1993. Family Sciuridae. In: Wilson DE, Reeder DM (eds) Mammal species of the world: a taxonomic and geographic reference. Smithsonian Institution Press, Washington, DC, p 455

Johnson DH, Jones JK., 1955. A new chipmunk from Korea. Proc Biol Soc Wash, 68, 175-176

Koh HS, Wang Jinxing, Lee BK, Yang BG, Heo SW, Jang KH, Chun TY., 2009. A Phylogroup of the Siberian Chipmunk from Korea (Tamias sibiricus barberi) Revealed from the Mitochondrial DNA Cytochrome $b$ Gene, Biochem Genet, 47 , $1-7$.

Korea National Park Research Institute., 2013. Korea National Park Wildlife Roadkill reduction measures Report, 28-33.

Lee HTK, Kemp Zarine., 1997. Towards a multiple placement land suitability evaluation framework, en M.J. Kraak y M. Molenaar (Eds.). Advances in GIS Research II, Taylor \& Francis Ltd, London.

Lee YW, Lee MW., 2006. Eco-corridor Positioning for Target Species, Journal of Korean Env. Res. \& Reveg. Tech., 9(3), 5158.

Ministry of Environment, 2004, Natural Environment Survey, 281-294.

Noss RF., 1993. Wildlife corridors. Pages 43-68 in D. S. Smith and P. C. Hellmund, editors. Ecology of Greenways. University of Minneapolis Press, Minneapolis, Minnesota, USA.

Park JJ, Woo DG, Oh DH, Park CH., 2012. Site Selection of Wildlife Passage for Leopard Cat in Urban Area using Space Syntax, Journal of the Korean Institute of Landscape Architecture, 40(1), 92-99.

Road Environmental Research Institute, 1995, "Constructing Road aimed to the Symbiosis with Nature: Eco-road Handbook", 16-23; 54-68; 132

Shin SA, Ahn TM., 2008. Approach to the Location of Wildlife Corridors on Highways, The Korea Society For Environmental Restoration And Revegetation Technology, 11(2), 19-27.

Yoon MH, Han SH, Oh HS, Kim JK, Park JG., 2004. The Mammals of Korea, 109-110.

Yoon MH., 1992. Wild Animals, 66-69. 